\title{
Differences between Rates of Metabolism of Benzene Hexachloride in Resistant and Susceptible Houseflies
}

In a previous commumication ${ }^{1}$, the metrbolism of $\gamma$-BHC was deseribed after injection into threo st rains of fies : a susceptible strain $\left(S^{\prime}\right)$, a strain resistant to $\gamma$ - BHC $\left(R_{1}\right)$, and a struin resistant to $\gamma$-BHC and DDC $\left(R_{2}\right)$.

The rate of metabolism in the wusceptible strain was not comparable with that of the resistant strains, since the former died rapidly, whereas the latter remained unaffectod. Thus it was impossible to tell whether the difference in motubolism could be a cause of the difference in susceptibjlity.

Hitherto, the mothod of estimation did not permit the sturly of the metabolism at doses low enough to leave also strain is unaffected. However, the problem becomes ancessible for experimentation if we assumo that all isomers of BHC wre metabolized by the same mechanism. 'J'hen the breakriown in the strains can be sturlied in comparable circumstances, as it is possible to estimate the $\alpha$ - and $\delta$-isomer at roncentrations that are not. at all toxic to the flies.

The flies were injecterl into the thorax with $\mathrm{BHC}$ in an cmulsion of peanut oil, and kept at $25^{\circ} \mathrm{C}$. for varying perriods of time, after which the amount of

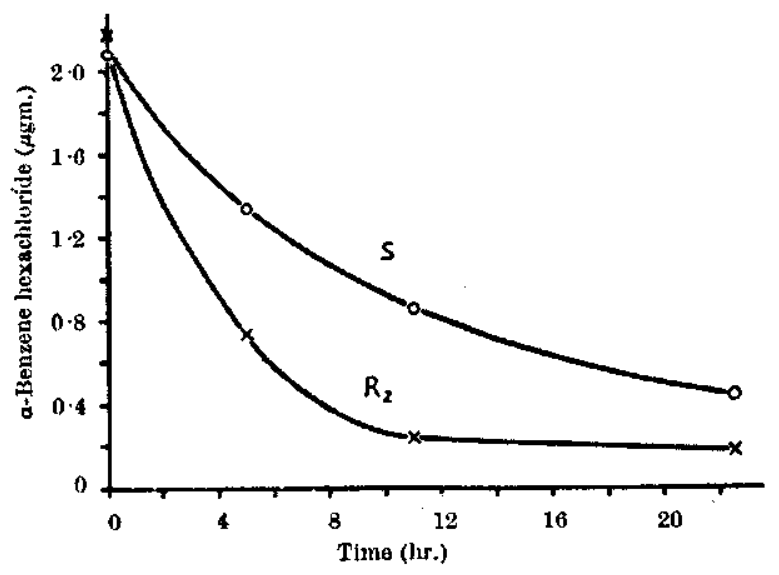

Fig. 1. Amount of a-BHC per fly plotted againat time after injection. $S$, susceptible strain ; $R_{2,} \gamma$-3HHO and DDT-resistant strain. Fifteen flies used for each estimation 
Table 1, BrbakDown of a- AND d-BHC

Thirty fies used for each estimation; horizontal lines represent injeetions on the same day

\begin{tabular}{|c|c|c|c|c|c|}
\hline Isomer & $\begin{array}{l}\text { Amount } \\
\text { injoeted } \\
\text { per fly } \\
(\mu \mathrm{mm} .)\end{array}$ & $\begin{array}{l}\text { Time between } \\
\text { injection and } \\
\text { estimation } \\
\text { (hr.) }\end{array}$ & \multicolumn{3}{|c|}{$S^{\stackrel{\text { Breakdown }}{\text { (per cent) }}{ }_{R_{x}} R_{1}}$} \\
\hline$a$ & $\begin{array}{l}0.83 \\
0.93 \\
0.67 \\
2.34 \\
2.34 \\
2.34 \\
2.34\end{array}$ & $\begin{array}{l}4 \\
4 \\
4 \\
5 \\
5 \\
5 \\
5\end{array}$ & $\begin{array}{l}36 \\
36 \\
45 \\
34 \\
43 \\
40 \\
23\end{array}$ & $\begin{array}{l}60 \\
57 \\
55 \\
- \\
57 \\
50\end{array}$ & $\begin{array}{l}80 \\
57 \\
65 \\
57 \\
71 \\
69\end{array}$ \\
\hline b & $\begin{array}{l}2 \cdot 34 \\
2 \cdot 34 \\
2 \cdot 34 \\
2 \cdot 34 \\
2 \cdot 34\end{array}$ & $\begin{array}{l}18 ! \\
18 ! \\
18 ! \\
18 ! \\
18 !\end{array}$ & $\begin{array}{l}28 \\
29 \\
25 \\
27 \\
27\end{array}$ & $\begin{array}{l}43 \\
32 \\
32 \\
46 \\
39\end{array}$ & $=$ \\
\hline
\end{tabular}

BHC was estimated. The results are presented in Fig. I and Table 1. It is shown that there is a difference in breakdown of the $\alpha$-and $\delta$-inomer between ' the susceptible and resistant strains. This difference is somewhat larger in the case of the $\alpha$-isomer. The breakdown of the $\delta$.isomer is markedly slower than that of the $\alpha$-isomer. As for technical reasons the experiments were not extended beyond $24 \mathrm{hr}$, it was impossible to obtain the complete breakdown curve for this isomer.

If our hypothesis is correct, the difference in rate of breakdown of $\gamma$-BHC between the susceptible and resistant strains has two causes: (1) a difference in breakdown capacity -a poesible cause of difference in susceptibility; (2) a decreasing rate of breakdown in the susceptible etrain as a result of the toxic action of $\gamma-\mathrm{BHC}-\mathrm{an}$ effect of the susceptibility.

If we assume that the metabolism results in $\mathbf{a}$ de. toxication, it is very probable that the difference in metabolism is a cause of the difference in susceptibility, although it is as yet impossible to estimate its importance. For example, it is not known how the rate of breakdown affects the concentration at the site of action. Work with more strains will perhaps be helpful in judging the significance of rate of break. down for resistance, as it may reveal whether there exists a correlation between capacity of breakdown and level of resistance.

F. J. OPPENOORTH

Laboratory for Research on Biocides, National Council for Agricultural Research T.N.O., Vondellean 6, Utrecht. Oct. 4.

Oppenoorth, F. J., Nature, 173, 1000 (1954). 